\title{
YM753, a novel histone deacetylase inhibitor, exhibits antitumor activity with selective, sustained accumulation of acetylated histones in tumors in the WiDr xenograft model
}

\author{
NOBUAKI SHINDOH ${ }^{1}$, MASAMICHI MORI ${ }^{1}$, YOH TERADA ${ }^{1}$, KAZUO ODA $^{1}$, NOBUAKI AMINO ${ }^{1}$, \\ AYA KITA ${ }^{1}$, MASATOSHI TANIGUCHI ${ }^{1}$, KIN-YA SOHDA ${ }^{1}$, KOJI NAGAI ${ }^{1}$, YOSHIHIRO SOWA ${ }^{2}$, \\ YUHTA MASUOKA $^{1}$, MASAYA ORITA ${ }^{1}$, MASAO SASAMATA ${ }^{1}$, HITOSHI MATSUSHIME ${ }^{1}$, \\ KIYOSHI FURUICHI ${ }^{1}$ and TOSHIYUKI SAKAI ${ }^{2}$ \\ ${ }^{1}$ Drug Discovery Research, Astellas Pharma Inc., 21 Miyukigaoka, Tsukuba, Ibaraki 305-8585; \\ ${ }^{2}$ Department of Molecular-Targeting Cancer Prevention, Graduate School of Medical Science, \\ Kyoto Prefectural University of Medicine, Kawaramachi-Hirokoji, Kamigyo-ku, Kyoto 602-8566, Japan
}

Received August 13, 2007; Accepted October 5, 2007

\begin{abstract}
Histone deacetylase (HDAC) inhibitors have been shown to have antitumor activity in vitro and in vivo. Various studies related to their antitumor activity and mechanism of action have been reported for HDAC inhibitors, but the relationship of their antitumor effects to their pharmacodynamic and pharmacokinetic properties in vivo has not ever fully characterized. We report here the discovery of a novel cyclic-peptide-based HDAC inhibitor, YM753. YM753 is a bacteria-derived natural product containing a disulfide bond. It potently inhibited HDAC enzyme with an $\mathrm{IC}_{50}$ of $2.0 \mathrm{nM}$ in the presence of dithiothreitol. YM753 was rapidly converted to a reduced form in tumor cells, and then induced accumulation of acetylated histones, followed by $\mathrm{p} 21^{\text {WAF1/Cip } 1}$ expression, tumor cell growth inhibition and tumor-selective cell death. In an in vitro washout study, YM753 showed prolonged accumulation of acetylated histones in WiDr human colon carcinoma cells. In vivo YM753 dosing of mice harboring WiDr colon tumor xenografts significantly inhibited the tumor growth via sustained accumulation of acetylated histones in the tumor tissue. In a pharmacokinetic
\end{abstract}

Correspondence to: Dr T. Sakai, Department of MolecularTargeting Cancer Prevention, Graduate School of Medical Science, Kyoto Prefectural University of Medicine, Kawaramachi-Hirokoji, Kamigyo-ku, Kyoto 602-8566, Japan

E-mail: tsakai@koto.kpu-m.ac.jp

Dr N. Shindoh, Institute for Drug Discovery Research, Astellas Pharma Inc., 21 Miyukigaoka, Tsukuba, Ibaraki, Japan

E-mail: nobuaki.shindoh@jp.astellas.com

Key words: histone deacetylase inhibitor, YM753, cyclic peptide, prodrug study, YM753 rapidly disappeared from the plasma, but its reduced form remained in the tumor tissue. Moreover, the accumulation of acetylated histones induced by YM753 was tumor tissue selective compared to several normal tissues. This study provides evidence that YM753 has antitumor activity that is the result of selective, sustained accumulation of acetylated histones in tumor tissues despite rapid disappearance of the drug from the plasma. These results suggest that the novel HDAC inhibitor, YM753 has attractive pharmacodynamic and pharmacokinetic properties giving it potential as an antitumor agent.

\section{Introduction}

Aberrant gene expression due to altered histone deacetylase (HDAC) activity has been associated with cancer. Tumortissue-specific histone hypoacetylation was observed in solid cancers of several patients, but not in their normal tissues $(1,2)$. Up-regulated expression of HDAC1, HDAC2 and HDAC3 has been reported in human colon tumors (3-5). Abnormal recruitment of HDACs by mutant transcription factors formed by chromosomal translocation also occurs in various leukemias (6).

Several structural classes of HDAC inhibitors have been characterized, including short-chain fatty acids (i.e., sodium butyrate, phenyl butyrate and valproic acid), hydroxamic acids (i.e., trichostatin A, SAHA (suberoylanilide hydroxamic acid), NPV-LAQ824, LBH589, PXD101, CRA024781, JNJ16241199 and A-161906), benzamides (i.e., MS-275, CI-994 and MGCD0103) and cyclic peptides (i.e., trapoxin, apicidin and FK228) (7-9). It is well established that HDAC inhibitors affect several cellular processes that are dysregulated in neoplastic cells. HDAC inhibitors cause growth inhibition with cellular differentiation, cell cycle arrest and cell death in a broad spectrum of tumor cells, while normal cells remain relatively resistant to these agents (10-12). They also inhibit angiogenesis (13). Other research groups and ourselves found that HDAC inhibitors activate 
transcription of the $\mathrm{p} 21^{\mathrm{WAF} 1 / \mathrm{Cip} 1}$ gene (14-16), and this induction is probably due to epigenetic regulation of the $\mathrm{p} 21^{\mathrm{WAF} 1 / \mathrm{Cip} 1}$ promoter associated with class I HDACs. HDAC inhibitors can also up-regulate proapoptotic pathways and down-regulate prosurvival pathways. Other studies have shown that HDAC inhibitors can induce both mitochondriamediated apoptosis and caspase-independent autophagic cell death (17-20). Various HDAC inhibitors, including SAHA, LBH589, PXD101, CRA-024781, MS-275, CI-994, MGCD0103 and FK228, are currently undergoing clinical trials in the treatment of various solid and hematological tumors $(9,21)$. In Phase I and II studies, SAHA has shown significant antitumor activity in patients with hematologic and solid tumors (22-24) and has recently been approved by the U.S. Food and Drug Administration (FDA) for the treatment of cutaneous T-cell lymphoma (25). In addition, FK228 achieved dramatic responses in peripheral and cutaneous T-cell lymphoma in a clinical study (26). These observations indicate that HDAC inhibitors are very promising as anticancer drugs $(9,21)$.

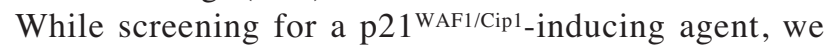
discovered that YM753 and 4 of its derivatives have potent inducing activity for $\mathrm{p} 21^{\mathrm{WAF} 1 / \mathrm{Cip} 1}$ gene expression. YM753 was named spiruchostatin A and it demonstrated TGF-ß-like activity in the culture broth of Pseudomonas fluorescens Q71576 (27). In this report, we describe that YM753, a novel bacteria-derived and cyclic-peptide-based HDAC inhibitor containing a disulfide bond, has unique pharmacodynamic and pharmacokinetic properties in vitro and in vivo.

\section{Materials and methods}

Agents. YM753 and 4 derivatives were isolated from the culture broth of Pseudomonas fluorescens Q71576 (27), while FK228 was isolated from the culture broth of unidentified bacterium Q43395. The reduced form of YM753 (RedYM), its glutathione-conjugate, YM-340209, and YM-349972 were prepared, and other HDAC inhibitors, including SAHA, NPV-LAQ824, LBH589, MS-275 and CI-994, were synthesized in Astellas Pharma Inc. Trichostatin A was purchased from Wako Pure Chemical Industries, Ltd. (Osaka, Japan) (Table I).

Cells. The following human cell lines were obtained from the American Type Culture Collection: WiDr (colon), A549 (lung), Calu-3 (lung), DMS53 (lung), DMS114 (lung), HOS (osteosarcoma), Saos2 (osteosarcoma), SK-MEL-28 (melanoma), MIAPaCa-2 (pancreas), MDA-MB-231 (breast), MDA-MB-468 (breast), UM-UC-3 (bladder), HL-60 (leukemia), WI-38 (normal lung) and WI-38VA13 (SV40transformed WI-38). K562 (leukemia), A2780 (ovary) and NHLF (Normal Human Lung Fibroblast) were obtained from RIKEN Cell Bank, Dainippon Sumitomo Pharma and Cambrex, respectively. These cells were maintained in appropriate media supplemented with FBS and antibiotics.

HDAC inhibition assay. The HDAC fraction, which contains multiple HDAC enzymes, was partially purified from the nuclear extract of a human leukemia cell line, K562, by a modification of the method of Yoshida et al (28). For evaluation of a panel of HDAC inhibitors, HDAC assay was performed using a CycLex HDACs Deacetylase Fluorometric Assay Kit (CycLex, Ina, Japan) according to the manufacturer's instructions, with slight modification. Briefly, after pre-incubation of compounds with the assay buffer containing $60 \mu \mathrm{M}$ dithiothreitol (DTT) for $1 \mathrm{~h}$, the HDAC reaction was carried out at room temperature. After $30 \mathrm{~min}$ of reaction, the fluorescence was measured using an excitation wavelength of $355 \mathrm{~nm}$ and a detection wavelength of $460 \mathrm{~nm}$. For evaluation of methylthio group derivatives, tritium-labeled acetyl-histone $\mathrm{H} 4$ peptide [(biotin-GlyAla-[ $\left[{ }^{3} \mathrm{H}\right.$-acetyl] Lys-Arg-His-Arg-[ $\left[{ }^{3} \mathrm{H}\right.$-acetyl $]$ Lys-Valamide, $90 \mathrm{Ci} / \mathrm{mmol}$; Amersham Pharmacia (29)] was used as a substrate for HDAC. HDAC assay was performed as previously reported (28), under DTT-free conditions. Briefly, compounds were incubated with $37 \mathrm{nM}\left[{ }^{3} \mathrm{H}\right]$-acetyl-histone $\mathrm{H} 4$ peptide in HDA buffer (15 mM potassium phosphate, $\mathrm{pH} 7.5,5 \%$ glycerol, $0.2 \mathrm{mM}$ EDTA) without DTT, and then the HDAC reaction was carried out at room temperature for $30 \mathrm{~min}$. The reaction was stopped with $\mathrm{HCl}$, the released $\left[{ }^{3} \mathrm{H}\right]$-acetic acid was extracted with ethylacetate, and the radioactivity in the solvent layer was measured with a liquid scintillation counter.

Molecular modeling and docking study. Using the program, MOE (MOE version 2003.02; Chemical Computing Group: Montreal 2003), a homology model was created from the sequence alignment between human HDAC1 and HDAC-like protein using the coordinates of the recently determined HDAC-like protein (30) as the template. A docking study of RedYM with the modeled human HDAC1 was performed using the GOLD program (31).

Detection of RedYM by HPLC in vitro. To detect RedYM in K562 cells, a cell lysate was prepared by treatment with $90 \mu \mathrm{M}$ YM753 for 10 and $50 \mathrm{~min}$ and brief sonication. To characterize the reduction mechanism, YM753 was incubated at a concentration of $100 \mu \mathrm{M}$ with the K562 lysate or the lower fraction of the K562 lysate obtained with a Microcon YM-3 Centrifugal Filter Unit or with $1 \mathrm{mM}$ glutathione solution at $37^{\circ} \mathrm{C}$ for $1 \mathrm{~h}$. HPLC analysis was performed against the lower fraction after treatment with Microcon YM-3. YM753 (SS), RedYM (SH) and glutathione-conjugated RedYM (SG) were used as standards in the HPLC analysis.

Induction of accumulation of acetylated histones $p 21^{\text {WAFI/Cipl }}$ protein and Rb hypophosphorylation in tumor cells. WiDr cells were treated with various concentrations of YM753 for $24 \mathrm{~h}$. Histone proteins were prepared using sulfuric acid as described previously (28), and cell lysates were prepared in ice-cold TNE buffer (10 mM Tris- $\mathrm{HCl}, \mathrm{pH} 7.8,1 \%$ NP-40, $150 \mathrm{mM} \mathrm{NaCl}$, Complete Mini (Roche), $10 \mu \mathrm{g} / \mathrm{ml}$ aprotinin containing $1 \mathrm{mM} \mathrm{NaF}$ and $1 \mathrm{mM} \mathrm{Na}_{3} \mathrm{VO}_{4}$ as phosphatase inhibitors). Immunoblotting was performed using antiacetylated histone $\mathrm{H} 3$ and anti-acetylated histone $\mathrm{H} 4$ antibodies (Upstate Biotechnology), anti-p21 WAF1/Cip1 antibody (Santa-Cruz), anti-Rb antibody (Pharmingen), anti-actin antibody (SIGMA) and appropriate secondary antibodies. To verify equal histone protein loading, a parallel gel was run and stained with Coomassie Brilliant Blue (CBB). 
Table I. HDAC inhibitory effects of YM753 and other HDAC inhibitors.

\begin{tabular}{lc}
\hline Compound & $\mathrm{IC}_{50}(\mathrm{nM})$ \\
\hline YM753 & $2.0 \pm 0.2$ \\
FK228 & $3.1 \pm 0.1$ \\
Trichostatin A & $5.2 \pm 0.4$ \\
SAHA & $108.8 \pm 11.3$ \\
NPV-LAQ824 & $8.1 \pm 0.9$ \\
LBH589 & $13.1 \pm 1.5$ \\
MS-275 & $>10,000$ \\
CI-994 & $>10,000$ \\
\hline
\end{tabular}

The HDAC reaction was performed in the presence of DTT. The experiment was performed in triplicate four times for each concentrations, and the inhibitory concentrations of $50 \%$ are shown as the mean $\pm \operatorname{SEM}(n=4)$.

Cell death analysis. After treatment of WiDr cells with various concentrations of YM753 for $36 \mathrm{~h}$, cell lysates were prepared in ice-cold TNE buffer. Then immunoblotting was performed using anti-PARP antibody (Cellsignaling), anti-procaspase 3 and anti-cleaved caspase 3 antibodies (Cellsignaling), anti-actin antibody (Sigma) and appropriate secondary antibodies.

LDH release assay. A549, NHLF, WI-38VA13 and WI-38 cells were treated for $48 \mathrm{~h}$ with various concentrations of YM753 or $0.2 \%$ Tween-20, which was the positive control reagent for lactate dehydrogenase (LDH) release. Then $\mathrm{LDH}$ release into the culture medium was measured using the LDH-cytotoxic test Wako (Wako Pure Chemical Industries, Japan) according to the manufacturer's instructions. All data show the percent of total LDH release, as the mean \pm SEM $(\mathrm{N}=4)$. Phase-contrast image photographs of A549 and NHLF were taken after 48-h treatment with YM753.

Cell growth inhibition assay. After 48-h treatment of the 14 cell lines shown in Table II with various concentrations of YM753, the cell counts were determined by sulforhodamine B (SRB) assay as previously reported (32). The concentrations required to inhibit cell growth by $50 \%\left(\mathrm{GI}_{50}\right)$ were calculated by logistic analysis.

In vitro washout study. WiDr cells were treated with $30 \mathrm{nM}$ YM753, $10 \mathrm{nM}$ FK228, $20 \mu \mathrm{M}$ SAHA and $20 \mu \mathrm{M}$ MS-275 for $12 \mathrm{~h}$, washed 3 times with DMEM and then cultured in DMEM containing 10\% FBS. At 1, 6, 12, 24, 48, 72 and $96 \mathrm{~h}$ after washing, histone proteins were extracted using sulfuric acid as described above and immunoblotting was carried out using anti-acetylated histone $\mathrm{H} 3$ antibody. To verify equal histone protein loading, a parallel gel was run and stained with CBB.

Antitumor study in a xenograft model. Male nude mice (five weeks of age) were purchased from Charles River Japan,
Table II. Growth inhibitory effect of YM753 on various tumor cells.

\begin{tabular}{llc}
\hline Cell line & Tumor type & $\mathrm{GI}_{50}(\mathrm{nM})$ \\
\hline Calu-3 & Lung & 1.6 \\
DMS53 & Lung & 2.3 \\
HOS & Osteosarcoma & 3.8 \\
Saos2 & Osteosarcoma & 4.5 \\
WiDr & Colon & 5.0 \\
SK-MEL-28 & Melanoma & 5.0 \\
MIAPaCa-2 & Pancreas & 5.7 \\
MDA-MB-231 & Breast & 6.0 \\
A2780 & Ovary & 6.1 \\
DMS114 & Lung & 6.4 \\
K562 & Leukemia & 11 \\
MDA-MB-468 & Breast & 12 \\
UM-UC-3 & Bladder & 15 \\
HL60 & Leukemia & 16 \\
\hline
\end{tabular}

The experiment was performed in triplicate and the growth inhibitory concentrations of $50 \%$ are shown.

Inc., and used after several days of acclimation. A single-cell suspension of WiDr $\left(2 \times 10^{6}\right.$ cells $)$ was inoculated into the flank of the mice by s.c. injection. The tumor volume was calculated by the following formula: $1 / 2 \mathrm{x}$ (length) $\mathrm{x}$ (width) ${ }^{2}$. When the tumor reached about 100 to $200 \mathrm{~mm}^{3}$ in volume, YM753 (3 mg/kg) was dissolved in 20\% hydroxypropyl- $\beta-$ cyclodextrin/saline and injected into the tail vein 3 times a week for 2 weeks (on days 0, 2, 4, 7, 9 and 11). The tumor size was measured twice a week (on days 3, 7, 10 and 14). Data are expressed as the mean tumor volume \pm SEM.

Pharmacodynamic study. YM753 was given as a single intravenous administration at a dose of $3 \mathrm{mg} / \mathrm{kg}$ to the WiDrbearing nude mice $(n=3)$. WiDr tumor tissue samples were removed from chloroform-anesthetized mice at 2, 4, 8, 24, 48 and $72 \mathrm{~h}$ after administration and kept at $-80^{\circ} \mathrm{C}$ until use. The tissues were crushed with a Cryo-Press (Microtec), and then histone proteins and cell lysates were prepared as described above. Immunoblotting was carried out using antiacetylated histone $\mathrm{H} 3$, anti-acetylated histone $\mathrm{H} 4$, anti$\mathrm{p} 21^{\mathrm{WAF} 1 / \mathrm{Cip} 1}$ and anti-actin antibodies. To verify equal histone protein loading, a parallel gel was run and stained with CBB. For examination of the status of acetylated histones in normal tissues, normal (colon, lung, prostate, small intestine, brain and heart) and WiDr tumor tissue samples were removed from chloroform-anesthetized WiDr-bearing nude mice at $8 \mathrm{~h}$ after a single intravenous administration of YM753 at a dose of $3 \mathrm{mg} / \mathrm{kg}$. Immunoblotting was performed using anti-acetylated lysine antibody (Upstate Biotechnology) for detection of acetylated histones (H2A, H2B, H3 and H4).

Pharmacokinetic study. YM753 was given as a single intravenous administration at $3 \mathrm{mg} / \mathrm{kg}$ to the WiDr-bearing 
A

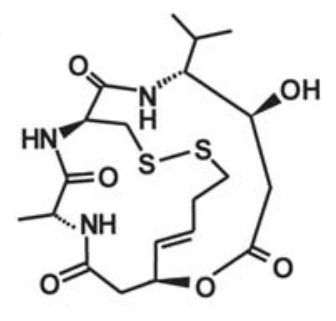

YM753

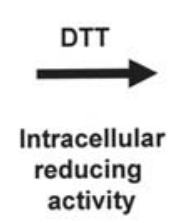

B

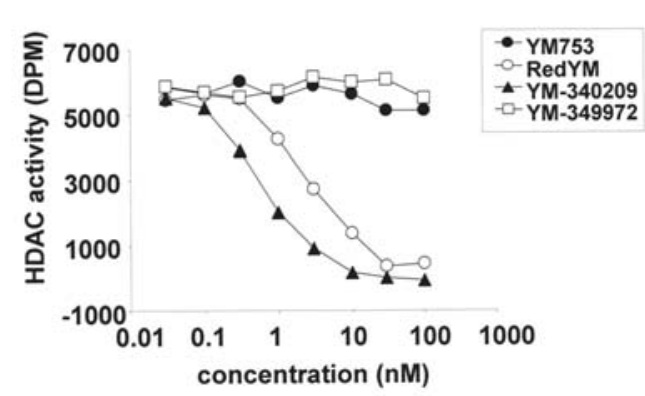

C

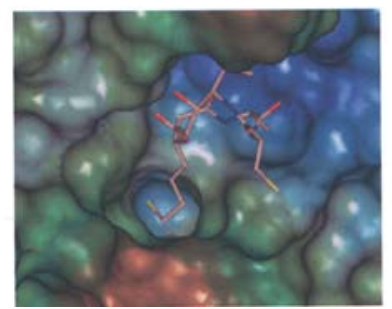

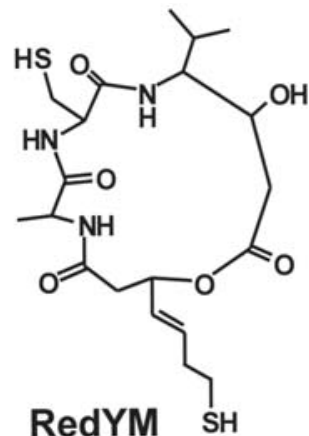

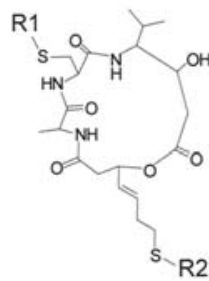

RedYM R2

YM-340209 H H

YM-349972 H Me

Figure 1. Effect of YM753 on HDAC. (A) Structures of YM753 and RedYM. (B) Effect of YM753 on HDAC inhibition in the absence of DTT by using $\left[{ }^{3} \mathrm{H}\right]$-Ac histone $\mathrm{H} 4$ peptide. Each data point represents the mean of duplicate determinations. Structures of methylthio group derivatives of RedYM are shown. (C) Results of docking RedYM into the active site of modeled human HDAC1. The surface lipophilic potential of each protein is shown. The color ramps for lipophilicity range from brown (highest lipophilic area) to blue (highest hydrophilic area). These surfaces were generated using Sybyl, MOLCAD module (SYBYL version 6.8, Tripos: St. Louis 2002).

nude mice $(n=3)$. Mice were anesthetized with diethyl ether, and blood samples were collected from the inferior vena cava and immediately added to ice-cold PBS supplemented with $\mathrm{N}$-ethylmaleimide and dichlorvos. After mixing the blood slowly, the plasma was obtained by centrifugation. Plasma was added to $30 \mathrm{vol} \%$ formic acid at a ratio of 2 to $1(\mathrm{v} / \mathrm{v})$ and then mixed on a Vortex. The plasma samples were mixed with 50 vol\% acetonitrile and internal standard solution at a ratio of 3 to 1 to $1(\mathrm{v} / \mathrm{v})$ on ice and then mixed on a Vortex. The samples were centrifuged, and each supernatant was analyzed by LC-MS/MS together with calibration and quality control samples prepared from blank mouse plasma for determination of the plasma concentrations of YM753 and RedYM. To determine the tumor concentrations of YM753 and RedYM, tumor samples were collected and immediately stored at $-80^{\circ} \mathrm{C}$ until assay. Tumor homogenates prepared with ice-cold PBS supplemented with $\mathrm{N}$-ethylmaleimide and dichlorvos were mixed with acetonitrile and then centrifuged. The supernatant was evaporated and dissolved in the LCMS/MS mobile phase. After centrifugation of the samples, the supernatant was analyzed by LC-MS/MS together with calibration and quality control samples prepared from blank tumor samples.
Statistical analysis. Statistical analysis of the in vivo antitumor study was performed with Student's t-test. Differences on day 14 with $\mathrm{P}<0.001$ vs. the control were considered statistically significant.

\section{Results}

RedYM is the active form of YM753 in HDAC inhibition. We had previously identified YM753 and its YM-187754 derivative (spiruchostatin B) (27), and in the present study we have identified three more derivatives, YM-209139, YM-343242 and YM-343243. These compounds are bicyclic peptides containing a di- or trisulfide bond (Fig. 1A and data not shown). We discovered that these compounds have p21 WAF1/Cip1-inducing activity (data not shown), and we examined their inhibitory effects on partially purified human HDAC enzymes. YM753 and its derivatives showed HDAC inhibitory activity in the presence of a reducing agent, dithiothreitol (DTT), but not in the absence of DTT. Therefore, we think that this is evidence that YM753 is converted to its reduced form by DTT. To evaluate the HDAC inhibitory effects of these compounds and other known HDAC inhibitors, all subsequent HDAC assays were performed in 
A

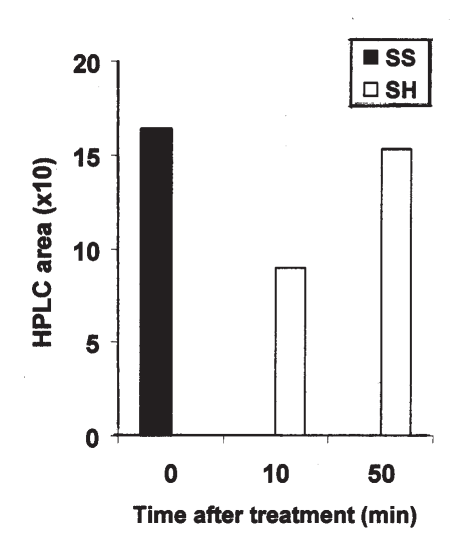

B

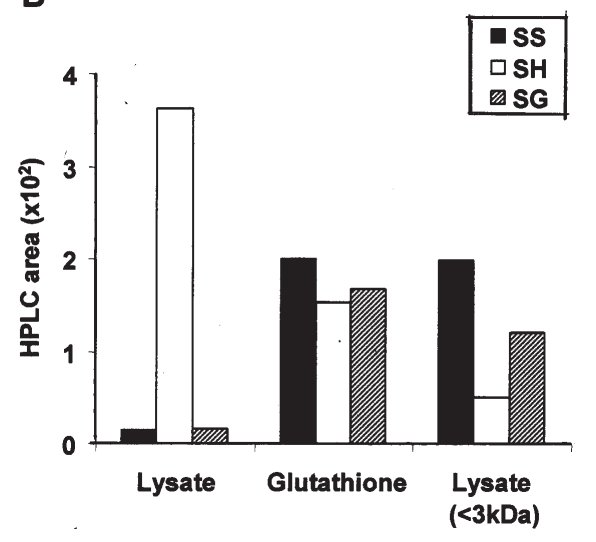

Figure 2. Characterization of the reduction of YM753 in K562 cells. (A) Detection of RedYM by HPLC. K562 cells were treated with $90 \mu$ M YM753 for the indicated times. For the 0-min control, YM753 was incubated with culture medium. YM753 and RedYM are represented as SS and SH, respectively. (B) Effect of K562 lysate and glutathione on the reduction of YM753. The indicated materials were incubated with $100 \mu \mathrm{M}$ YM753 for $1 \mathrm{~h}$ at $37^{\circ} \mathrm{C}$, and YM753 (SS), RedYM (SH) and glutathione-conjugated RedYM (SG) were analyzed.

the presence of DTT. The $\mathrm{IC}_{50}$ for the HDAC inhibitory activity of YM753 against the acetyl peptide substrate was $2.0 \mathrm{nM}$ and its derivatives showed similar activities (Table I and data not shown). YM753 was somewhat more potent than FK228, which is a structurally similar cyclic peptide containing a disulfide bond in its structure, and it was more potent than the compounds belonging to the hydroxamic acids (trichostatin A, SAHA, NPV-LAQ824 and LBH589) and benzamides (MS-275 and CI-994).

The dependence of HDAC inhibition on DTT was also observed for FK228 but not for the hydroxamic acids and benzamides (data not shown). We therefore postulated that disulfide bond reduction is necessary for the HDAC inhibitory activity of YM753 and FK228. To confirm this, the reduced form of YM753 (RedYM) was prepared, and its HDAC inhibitory activity was examined in the absence of DTT. RedYM strongly inhibited HDAC activity with an $\mathrm{IC}_{50}$ of $2.9 \mathrm{nM}$ (Fig. 1B). We therefore conclude that RedYM is the active form in HDAC inhibition.

To further examine the effect of the sulfhydryl groups of RedYM on its HDAC inhibitory activity, we prepared two derivatives of RedYM, i.e., YM-340209 and YM-349972, in which one of the sulfhydryl groups was converted to a methylthio group (Fig. 1B). YM-340209 inhibited HDAC activity with an $\mathrm{IC}_{50}$ of $0.6 \mathrm{nM}$, whereas YM-349972 showed no inhibition up to $100 \mathrm{nM}$ in the absence of DTT (Fig. 1B). This indicates that the sulfhydryl group in the long chain of RedYM contributes to HDAC inhibition. A docking study of RedYM using a known HDAC-like protein crystal structure (30) showed that the long chain of RedYM inserts into a tubular pocket of the HDAC1 enzyme and interacts with zinc via the sulfhydryl group at the end of the long chain (Fig. 1C).

YM753 is reduced in tumor cells. To examine whether YM753 undergoes reduction inside the cell, we performed HPLC analysis to detect YM753 and RedYM after treatment of cells with YM753. Since we expected that YM753 would be rapidly reduced in tumor cells, we used K562, a suspension-cultured human leukemia cell line, so that a cell extract could be prepared quickly. HPLC analysis revealed that only RedYM was detected at 10 and 50 min after the treatment, while no YM753 was detected (Fig. 2A). In a stability study, YM753 was found to be stable in culture medium at $37^{\circ} \mathrm{C}$ for $1 \mathrm{~h}$ (data not shown). These results indicate that YM753 is activated after it is incorporated into tumor cells, presumably as a result of intracellular reducing activity.

We next examined the mechanism by which YM753 is reduced in the cell. When YM753 was mixed with K562 lysate at $37^{\circ} \mathrm{C}$ for $1 \mathrm{~h}$, most of the YM753 was converted to RedYM (Fig. 2B). We then examined whether glutathione, an intracellular reducing substance, contributed to the reduction of YM753. After mixing YM753 with $1 \mathrm{mM}$ glutathione, which is close to its intracellular concentration, and incubating the mixture at $37^{\circ} \mathrm{C}$ for $1 \mathrm{~h}$, RedYM and glutathione-conjugated RedYM were produced, while unreacted YM753 remained (Fig. 2B). When YM753 was mixed with the $<3 \mathrm{kDa}$ lysate fraction obtained by centrifugation with the Microcon YM-3 Centrifugal Filter, the results of reacting this mixture were similar to the results for the glutathione-treated samples. Since glutathione is contained in the lower lysate fraction, the reaction results suggest that YM753 reacts with intracellular glutathione. However, those results indicate that glutathione is not sufficient alone, and one can speculate that some other protein(s) is necessary to reduce YM753 in tumor cells.

YM753 induces accumulation of acetylated histones, p21 $1^{\text {WAFI/Cipl }}$ expression and cell cycle arrest. To examine HDAC inhibition in tumor cells, we carried out immunoblot analysis using anti-acetylated histone antibodies against human colon cancer cells, WiDr, because it was reported that HDACs are overexpressed in colon tumor tissue and in this cell line (3-5). YM753 induced accumulation of acetylated histones $\mathrm{H} 3$ and $\mathrm{H} 4$ in time-dependent (data not shown) and dose-dependent fashion (Fig. 3A). Immunoblot analysis revealed that YM753 also increased the level of p21 WAF1/Cip1 protein in a dose-dependent manner (Fig. 3A), with a concomitant increase in hypophosphorylation of $\mathrm{Rb}$ in the cells. 
A
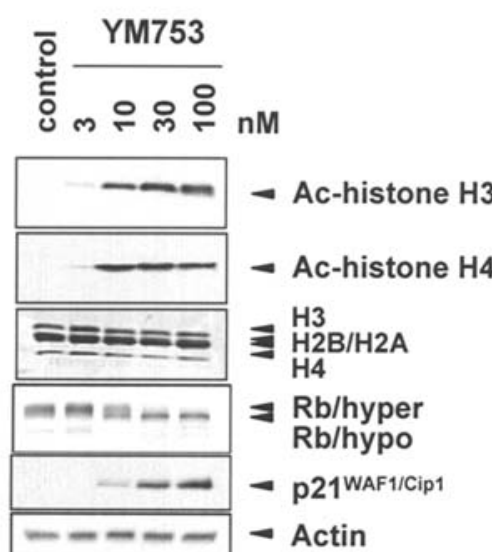

B

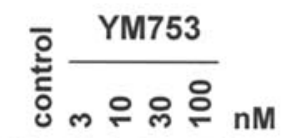

D
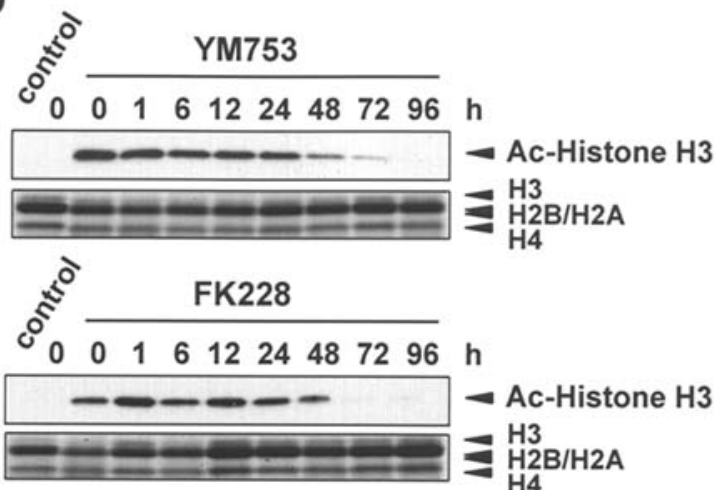

h

- Ac-Histone $\mathrm{H} 3$

$\equiv \mathrm{H}^{\mathrm{H}} 3$

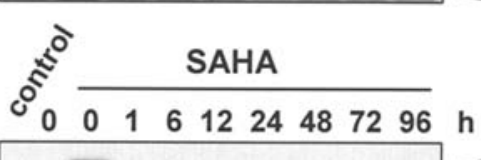

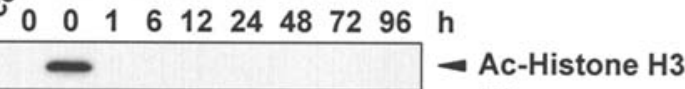

Ac-Histone ${ }_{\mathrm{H} 3}^{\mathrm{H}} \mathrm{B} / \mathrm{H} 2 \mathrm{~A}$
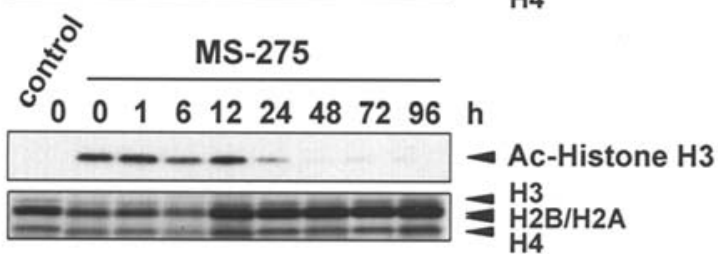

C
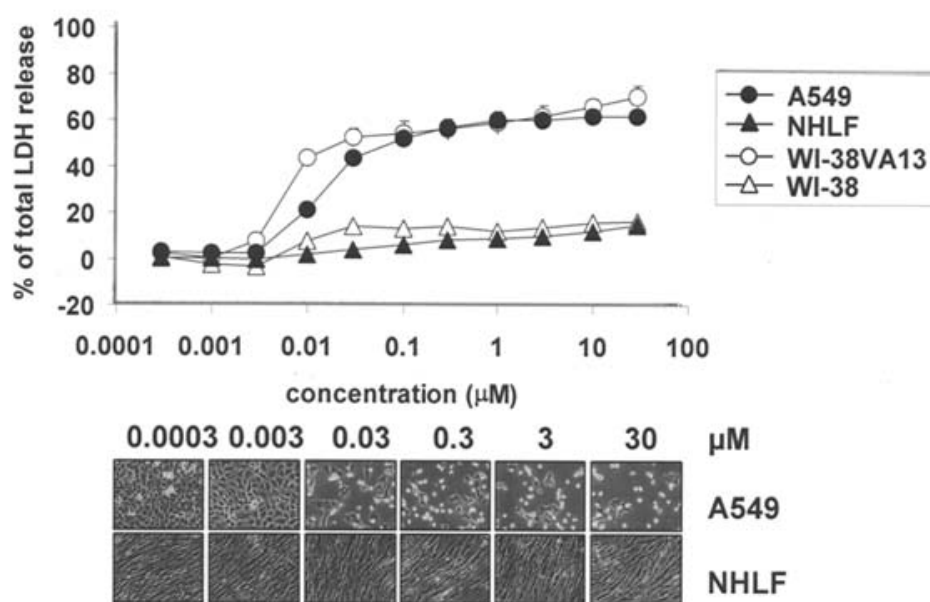

$\mu \mathrm{M}$

A549

NHLF

Figure 3. Effects of YM753 on induction of accumulation of acetylated histones, p21 ${ }^{\mathrm{WAF} 1 / \mathrm{Cip} 1}$ expression and cell cycle arrest. (A) WiDr cells were treated with $0.1 \%$ ethanol (control) or YM753 for $24 \mathrm{~h}$, followed by immunoblotting. In a parallel gel, histones $(\mathrm{H} 2 \mathrm{~A}, \mathrm{H} 2 \mathrm{~B}, \mathrm{H} 3$ and $\mathrm{H} 4)$ were stained with CBB as the loading control. (B) Effect of YM753 on activation of caspase 3 and cleavage of PARP. WiDr cells were treated with YM753 for 36 h, followed by immunoblotting. (C) Cytotoxicity for tumor and normal cells. LDH release from A549, NHLF, WI-38VA13 and WI-38 cells after treatment with YM753 for $48 \mathrm{~h}$ is shown (top). All data show the percent of total LDH release as the mean \pm SEM (N=4). The phase-contrast images of A549 and NHLF obtained under the same conditions are shown (bottom). (D) Duration of acetylated histone H3 accumulation by HDAC inhibitors after washing WiDr cells. WiDr cells were treated with YM753 (30 nM), FK228 $(10 \mathrm{nM})$, SAHA $(20 \mu \mathrm{M})$ or MS-275 $(20 \mu \mathrm{M})$ for $12 \mathrm{~h}$. After washing the cells three times with drug-free medium, they were cultured for the indicated times. Then histone proteins were extracted and immunoblotted using anti-acetylated histone H3 antibody. In a parallel gel, histones were stained with CBB.

Flow cytometric analysis was performed to examine the induction of cell cycle arrest in WiDr cells by YM753. YM753 at $30 \mathrm{nM}$, which is a higher dose than $\mathrm{GI}_{50}$ in WiDr (Table II), induced $\mathrm{G}_{1}$ and $\mathrm{G}_{2} / \mathrm{M}$ arrest after treatment for $24 \mathrm{~h}$ (data not shown).

YM753 induces cell death in tumor cells. To examine whether caspase 3 was activated in WiDr cells, we next performed immunoblot analysis using anti-caspase 3 and PARP antibodies. YM753 increased cleavage of caspase 3 and its substrate, PARP, in a dose-dependent manner (Fig. 3B). However, YM753-induced cell death was not completely prevented by the pan-caspase inhibitor, zVAD-fmk (data not shown), this suggests that YM753-induced WiDr cell death exhibits combined features of caspase-dependent apoptosis and caspase-independent cell death.

YM753 exhibits selective cytotoxicity between tumor and normal cells. It was reported that the cell death induced by HDAC inhibitors is tumor-selective $(11,20,33)$. We performed 
A

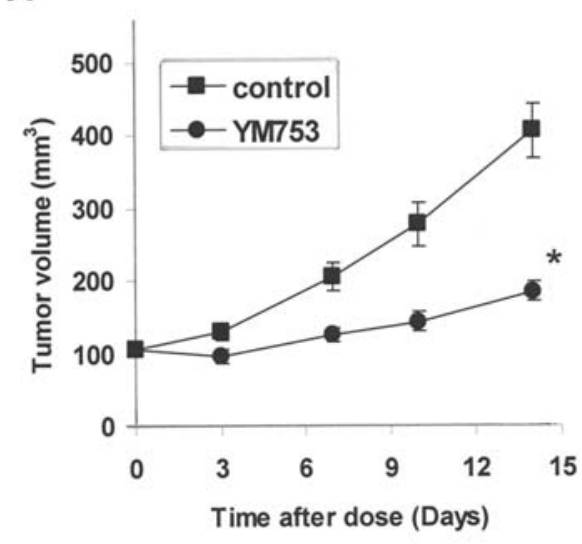

C

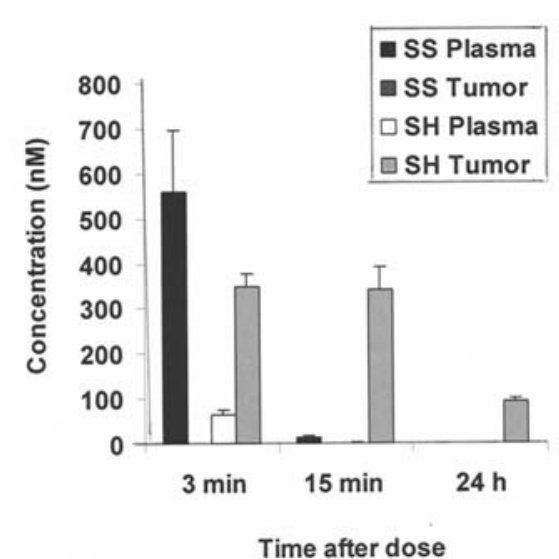

B

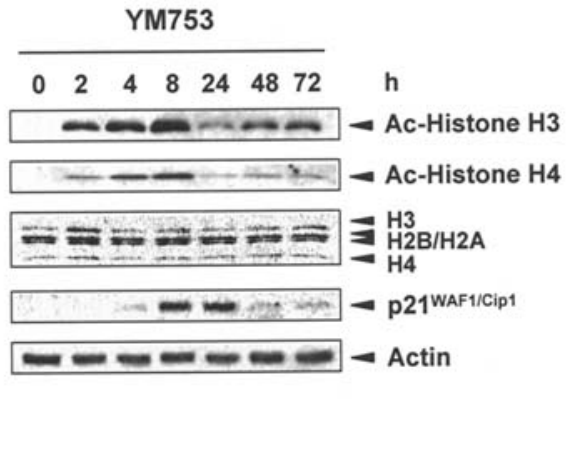

D

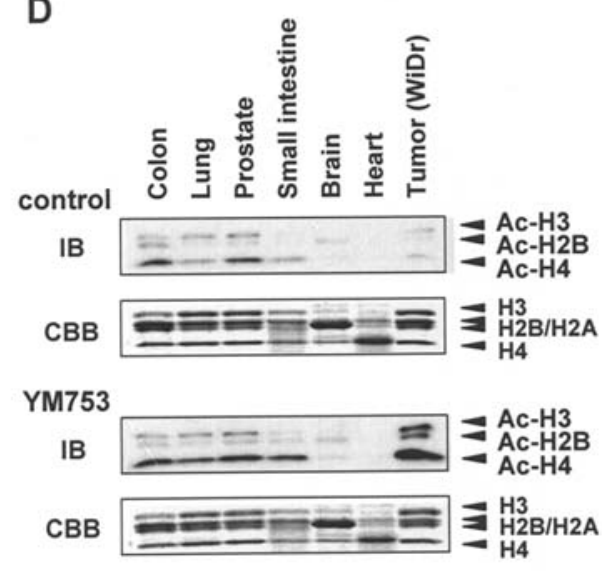

Figure 4. Characterization of antitumor effect of YM753 in vivo. (A) Antitumor activities of YM753 and RedYM in WiDr tumor xenografts in nude mice.

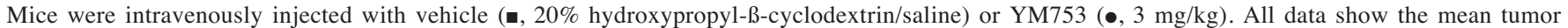
volume \pm SEM of 5 mice on days 3, 7, 10 and 14. Statistical analysis was performed using Student's t-test for the values on day 14 . ${ }^{*} \mathrm{P}<0.001$ vs. control. (B) Pharmacodynamic analysis of YM753 in WiDr tumor xenografts in nude mice. The statuses of acetylated histones H3 and H4 and $21^{\text {WAFl/Cip1 }}$ expression in WiDr tumor tissues after administration of YM753 (3 mg/kg) were determined by immunoblotting. In a parallel gel, histones (H2A, H2B, H3 and H4) were stained with $\mathrm{CBB}$ and actin protein was immunoblotted as a loading control. The experiment was performed in triplicate and representative data are shown. (C) Pharmacokinetic analysis of YM753 in WiDr tumor xenografts in nude mice. The concentrations of YM753 (SS) and RedYM (SH) in the plasma and tumor tissue after administration of YM753 (3 mg/kg) were determined. Concentrations are shown as the mean \pm SD for $3 \mathrm{mice}$. (D) Effects of YM753 on the accumulation of acetylated histones in tissues. The status of acetylated histones (H2A, H2B, H3 and H4) in normal tissues and the WiDr tumor 8 h after administration of YM753 (3 mg/kg) was determined by immunoblotting (IB) using anti-acetylated lysine antibodies. In a parallel gel, histones (H2A, H2B, $\mathrm{H} 3$ and $\mathrm{H} 4)$ were stained with $\mathrm{CBB}$.

an LDH release assay to examine the cytotoxicity of YM753 for tumor and normal cells. YM753 showed cytotoxic effects on A549, a human non-small cell lung carcinoma cell line, at $48 \mathrm{~h}$ after treatment, but the effect on NHLF, normal human lung fibroblasts, was modest up to $30 \mu \mathrm{M}$ YM753 (Fig. 3C). This profile of YM753 was confirmed by microscopic observation. In addition, similar selective effects were also observed with WI-38VA13 cells, which are SV40-transformed cells of WI-38 normal human lung fibroblasts. Thus, these results indicate that YM753 shows selective tumor cytotoxicity in vitro.

YM753 inhibits growth of a variety of human tumor cell lines. To evaluate the growth inhibitory activity of YM753 in tumor cell lines, the $\mathrm{GI}_{50} \mathrm{~s}$ were determined after $48-\mathrm{h}$ treatment using the sulforhodamine B (SRB) method. YM753 showed potent anti-proliferative activity in a broad range of human tumor cell types, and the $\mathrm{GI}_{50} \mathrm{~s}$ of YM753 ranged from 1.6 to $16 \mathrm{nM}$ (Table II).
YM753 shows prolonged duration of acetylated histone accumulation after washout in vitro. To examine the duration of the acetylated histone accumulation, we carried out a washout experiment after YM753 treatment of WiDr cells. The cells were treated with $30 \mathrm{nM}$ YM753 for $12 \mathrm{~h}$, removed and cultured in drug-free medium for 1, 6, 12, 24, 48, 72 and $96 \mathrm{~h}$. Immunoblot analysis revealed that accumulation of acetylated histone $\mathrm{H} 3$ was significantly increased at $12 \mathrm{~h}$ of treatment, and the increased level of acetylation was maintained for up to $72 \mathrm{~h}$ after washout of the compound (Fig. 3D). To examine whether this effect is a unique characteristic of YM753, we next compared the effects of several other HDAC inhibitors, i.e., FK228, SAHA and MS-275, on the duration of acetylated histone accumulation after treatment at $10 \mathrm{nM}, 20$ and $20 \mu \mathrm{M}$, respectively, concentrations at which YM753 showed almost the same effect on accumulation of acetylated histone H3 in WiDr cells. FK228, another cyclic-peptide-based inhibitor, also displayed prolonged histone acetylation for up to $48 \mathrm{~h}$ after 
washout, whereas SAHA, a hydroxamic-acid-based inhibitor, and MS-275, a benzamide-based inhibitor, showed decreased histone acetylation within at 1 and $24 \mathrm{~h}$ after washout, respectively (Fig. 3D).

YM753 has antitumor activity with selective, sustained accumulation of acetylated histones in tumor tissue in WiDr xenograft model. To investigate whether YM753 had antitumor activity in the WiDr xenograft model, mice bearing tumors were intravenously administered YM753 at $3 \mathrm{mg} / \mathrm{kg}$ or the vehicle, 3 times a week for 2 weeks (administered on days $0,2,4,7,9$ and 11). YM753 showed significant inhibition of tumor growth on day 14 (Fig. 4A). In addition, we examined whether RedYM, the active form of YM753, had similar antitumor activity at $10 \mathrm{mg} / \mathrm{kg}$, a higher dose than that of YM753, but RedYM showed no inhibitory activity in vivo (data not shown).

To examine the antitumor effect of YM753 on the basis of its HDAC inhibition, we investigated the induction of accumulation of acetylated histones and $\mathrm{p} 21^{\mathrm{WAF} 1 / \mathrm{Cip} 1}$ protein expression in WiDr tumor tissue after a single intravenous administration of YM753 at $3 \mathrm{mg} / \mathrm{kg}$. The acetylation of histones $\mathrm{H} 3$ and $\mathrm{H} 4$ in WiDr tumors increased from 2 to $8 \mathrm{~h}$ and gradually decreased after $8 \mathrm{~h}$, but was still observed even at $72 \mathrm{~h}$ after administration (Fig. 4B). The expression of $\mathrm{p} 21^{\mathrm{WAF} 1 / \mathrm{Cip} 1}$ protein increased up to $24 \mathrm{~h}$ and was detected at lower levels even at 48 and $72 \mathrm{~h}$. These results suggest that YM753 has antitumor activity based on HDAC inhibition in vivo. In addition, the above pharmacodynamic study indicates that YM753 induces sustained accumulation of acetylated histones in tumor tissue in the WiDr xenograft model.

To examine the mechanism of the sustained pharmacodynamic effect of YM753, we performed a pharmacokinetic study in the WiDr xenograft model. We have found that YM753 was a prodrug and was reduced to RedYM in tumor cells, the concentrations of YM753 and RedYM in the plasma and tumor were measured after a single intravenous administration of YM753 at $3 \mathrm{mg} / \mathrm{kg}$. The plasma concentrations of YM753 were $558 \mathrm{nM}$ at $3 \mathrm{~min}$ and $15 \mathrm{nM}$ at $15 \mathrm{~min}$. In addition, the RedYM levels in plasma were $65 \mathrm{nM}$ at $3 \mathrm{~min}$ and $1.3 \mathrm{nM}$ at $15 \mathrm{~min}$ (Fig. 4C). Although intra-tumoral YM753 was not detected at $3 \mathrm{~min}$, $15 \mathrm{~min}$ and $24 \mathrm{~h}$, RedYM was detected in the tumor at levels of 347, 341 and $92 \mathrm{nM}$, respectively. Thus, YM753 rapidly disappeared from the plasma, but after uptake into the tumor, its active metabolite remained in the tumor tissue for more than $24 \mathrm{~h}$.

We next examined how the above property affects tumor and normal tissues. After a single i.v. administration of YM753 at $3 \mathrm{mg} / \mathrm{kg}$ to WiDr xenograft nude mice, the tumor and several normal tissues, including the colon, lung, prostate, small intestine, brain and heart, were collected. The tails of core histones (H2A, H2B H3 and H4) have a number of lysine residues, and for this reason the status of acetylation of histones was examined using antiacetylated lysine antibody. In the vehicle control, the basal levels of acetylation of histones $\mathrm{H} 2 \mathrm{~B}, \mathrm{H} 3$ and $\mathrm{H} 4$ in several normal tissues were slightly higher than in the tumor tissue (Fig. 4D). After YM753 treatment, the acetylated histones $\mathrm{H} 2 \mathrm{~B}, \mathrm{H} 3$ and $\mathrm{H} 4$ were slightly increased in normal tissues, including the colon, lung, prostate and small intestine, compared with the vehicle control, but they were dramatically increased in the tumor tissue. We thus conclude that, in vivo, YM753 causes selective accumulation of acetylated histones in tumor tissues compared with normal tissues.

\section{Discussion}

In this report, we describe the characteristics of a novel cyclicpeptide-based HDAC inhibitor, YM753. YM753 induced histone acetylation followed by $\mathrm{p} 21^{\mathrm{WAF} 1 / \mathrm{Cip} 1}$ expression, $\mathrm{G}_{1}, \mathrm{G}_{2} / \mathrm{M}$ cell cycle arrest, apoptosis and caspaseindependent tumor cell death in WiDr cells. These observations are consistent with the properties of HDAC inhibitors $(11,15,20)$.

Co-crystallization of an HDAC-like protein and trichostatin A demonstrated that HDAC inhibitors mimic the substrate and that chelation of zinc in the catalytic pocket by the hydroxamic acid group is the main mechanism of inhibition (30). Consistent with the structure of the enzymeinhibitor complex, most HDAC inhibitors consist of cap, spacer and functional groups $(30,34)$. RedYM has a sulfhydryl group on a 4-carbon-long chain extending from the cyclic peptide core with the sulfhydryl group extending into the active pocket. It has been predicted, using dimethyl FK228, that the sulfhydryl group in the long chain of reduced FK228 (RedFK) is important in inhibiting HDAC enzymatic activity (35). Our study using mono-methylthio derivatives of RedYM showed directly that the sulfhydryl group in the long chain is necessary for HDAC inhibition, and furthermore, our docking study using the HDAC1 and RedYM complex supported this conclusion.

YM753 is rapidly reduced to RedYM by intracellular reducing activity in a human leukemia K562 cells. Cellular glutathione was determined to be the major factor in reduction of FK228 by studying glutathione biosynthesis mutants of fission yeast (35). Our current study suggests that a yet-unidentified molecule, possibly a protein(s) over $3 \mathrm{kDa}$ that is involved in intracellular reduction, such as thioredoxin and reductases, is also necessary to reduce YM753. Moreover, after pre-treatment with L-buthionine-S,R-sulphoximine (BSO), which inhibits the rate-limiting glutathione biosynthesis enzyme, $\gamma$-glutamylcysteine synthetase, in cells, the growth inhibitory effects of YM753 did not change in various tumor cell lines despite the decrease in the intracellular glutathione concentration (data not shown). It has been reported that components involved in intracellular reducing activity, such as thioredoxin and glutathione, are increased in tumor tissues and contribute to resistance to chemotherapy $(36,37)$ because of their functions in inactivation and export of anticancer drugs. Our study suggests that YM753 may be effective even against such drug-resistant tumors.

YM753 significantly inhibited tumor growth via accumulation of acetylated histones and $\mathrm{p} 21^{\mathrm{WAF} 1 / \mathrm{Cip} 1}$ protein in the WiDr xenograft model, whereas RedYM showed no antitumor effect. This finding suggests that acetylated histones may be accumulated more efficiently in tumors after administration of YM753 than after dosing of RedYM, 


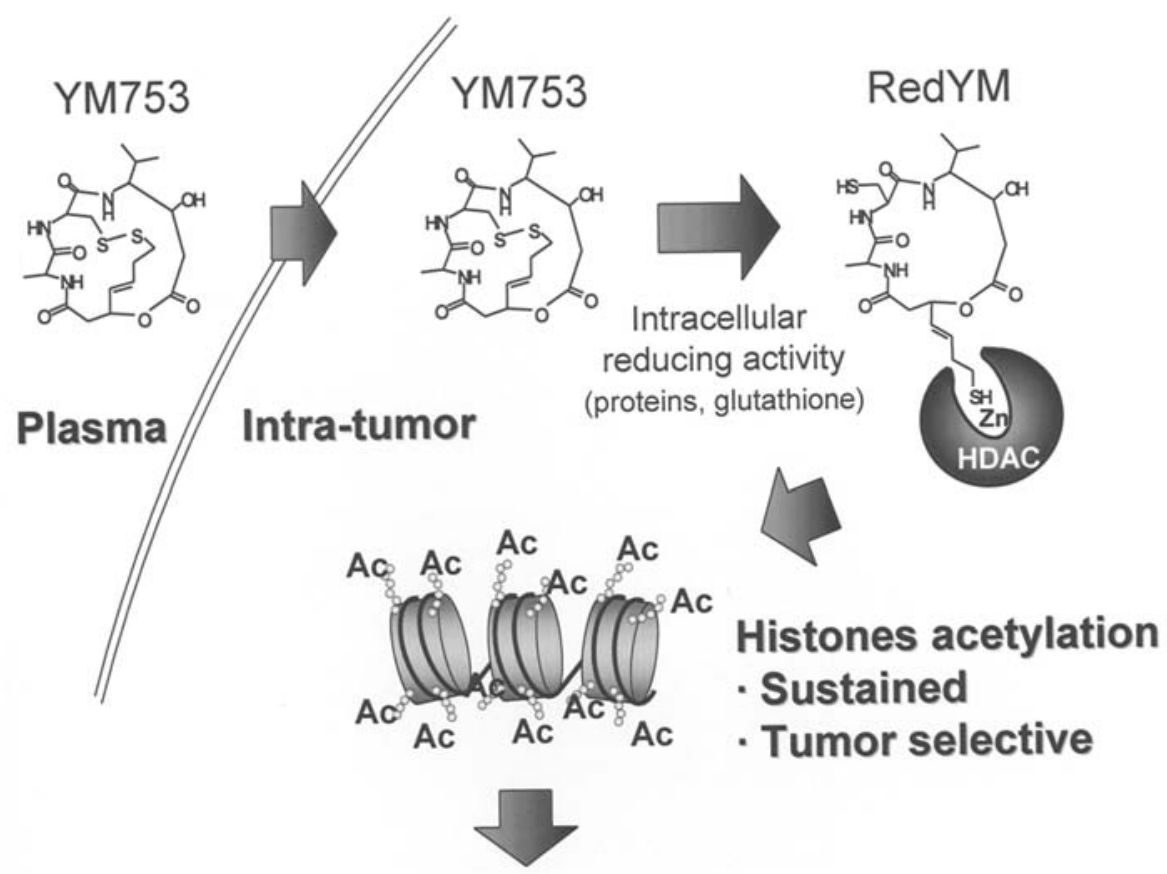

Antitumor effect

Figure 5. HDAC inhibitory effect of YM753 in the WiDr xenograft model.

and that it is necessary for YM753 to be administered in the prodrug form to have an in vivo antitumor effect.

In the pharmacokinetic study, YM753 disappeared rapidly from the plasma and was not observed in the tumor at 3, 15 min or $24 \mathrm{~h}$ after administration of YM753, whereas RedYM appeared in the tumor within 3 min after administration, suggesting that YM753 rapidly transfers to tumor tissues and is reduced to its active form (RedYM). In addition, RedYM remained in tumor tissues for $24 \mathrm{~h}$ at a concentration at which YM753 was fully able to induce histone acetylation in WiDr cells. This observation is consistent with the result that accumulation of acetylated histones in tumor tissues is detected at $2 \mathrm{~h}$ and persists for more than $24 \mathrm{~h}$ after administration of YM753.

The histone acetylation in tumor tissues induced by other HDAC inhibitors, such as SAHA, was reported to disappear by $12 \mathrm{~h}$ after a single intraperitoneal administration, and this shorter duration is consistent with SAHA's short halflife (15-20 min) (38). It has been documented that HDAC inhibitors belonging to the hydroxamic acids have poor bioavailability in vivo due to extensive biotransformation and/or a short half-life $(21,39)$. Therefore, there is a need for inhibitors that have improved pharmacokinetic properties (39). HDAC inhibitors such as SAHA and MS-275, when orally administered, have substantially longer half-lives in the plasma and elicit a better clinical response, but they are also more toxic (9). We have discovered that YM753 has an attractive profile of inducing sustained accumulation of acetylated histones in tumor tissues despite its rapid disappearance from the plasma. We expect that the prodrug form is an important factor underlying this unique pharmacodynamic profile, because administration of RedYM showed absolutely no antitumor activity in the xenograft model. Our in vitro washout experiment strongly suggests that the sustained accumulation of acetylated histones observed after administration of YM753 in vivo is due to the prolonged duration of histone acetylation seen in WiDr cells even after washout, and a similar prolonged duration of action was observed with FK228 but not with SAHA. In addition, we discovered that FK228 also has similar pharmacodynamic and pharmacokinetic properties in vivo (data not shown). The sustained pharmacodynamic property is characteristic to cyclic-peptide-based HDAC inhibitors containing a disulfide bond, such as YM753 and FK228. The sustained pharmacodynamic effect may be due to high stability and lasting affinity of these compounds for target molecule(s) and low efflux from the tumor cells and tissues.

On the other hand, YM753 dramatically induced accumulation of acetylated histones in tumor tissue compared with in several normal tissues. We can conceive two theories in explanation of YM753's selective histone acetylation in tumor tissues: i) YM753 may be selectively reduced to an active form in tumor tissues. There are several reports that intracellular reducing activity is higher in tumor tissues than in normal tissues $(40,41)$, suggesting that YM753 may be more efficiently reduced in tumor tissues. ii) YM753 may be selectively transferred to tumor tissues. Most solid tumors are known to exhibit extensive angiogenesis, hypervasculature and increased vascular permeability compared with normal tissues, permitting selective targeting of tumors by antitumor drugs. This phenomenon is known as the enhanced permeability and retention (EPR) effect (42) and YM753 may utilize the EPR effect for its transfer into tumor tissues. It will be necessary to examine the mechanism of YM753's tumor-selective accumulation of acetylated histones.

In conclusion, YM753 is a potent, cyclic-peptide-based HDAC inhibitor occurring as a bacteria-derived natural prodrug. YM753 expresses antitumor activity in vivo, with 
selective, sustained accumulation of acetylated histones in tumor tissues despite its rapid disappearance from the plasma in a xenograft model. These results indicate that YM753 is a novel HDAC inhibitor with unique and attractive pharmacodynamic and pharmacokinetic properties (Fig. 5) giving it potential as an antitumor agent.

\section{Acknowledgments}

We thank Drs. M. Shibazaki and N. Seki for the preparation of methylthio group derivatives. We also thank Drs. H. Hiyama and E. Ball for their skilled technical assistance.

\section{References}

1. Yasui W, Oue N, Ono S, Mitani Y, Ito R and Nakayama H: Histone acetylation and gastrointestinal carcinogenesis. Ann NY Acad Sci 983: 220-231, 2003.

2. Fraga MF, Ballestar E, Villar-Garea A, Boix-Chornet M, Espada J, Schotta G, Bonaldi T, Haydon C, Ropero S, Petrie K, Iyer NG, Pérez-Rosado A, Calvo E, Lopez JA, Cano A, Calasanz MJ, Colomer D, Piris MA, Ahn N, Imhof A, Caldas C, Jenuwein $\mathrm{T}$ and Esteller M: Loss of acetylation at Lys16 and trimethylation at Lys20 of histone $\mathrm{H} 4$ is a common hallmark of human cancer. Nat Genet 37: 391-400, 2005.

3. Huang BH, Laban M, Leung CH, Lee L, Lee CK, Salto-Tellez M, Raju GC and Hooi SC: Inhibition of histone deacetylase 2 increases apoptosis and p21Cip1/WAF1 expression, independent of histone deacetylase 1. Cell Death Differ 12: 395-404, 2005.

4. Zhu P, Martin E, Mengwasser J, Schlag P, Janssen KP and Gottlicher M: Induction of HDAC2 expression upon loss of APC in colorectal tumorigenesis. Cancer Cell 5: 455-463, 2004.

5. Wilson AJ, Byun DS, Popova N, Murray LB, L'Italien K, Sowa Y, Arango D, Velcich A, Augenlicht LH and Mariadason JM: Histone deacetylase 3 (HDAC3) and other Class I HDACs regulate colon cell maturation and p21 expression and are deregulated in human colon cancer. J Biol Chem 281: 13548-13558, 2006.

6. Johnstone RW: Histone-deacetylase inhibitors: novel drugs for the treatment of cancer. Nat Rev Drug Discov 1: 287-299, 2002.

7. Hess-Stumpp H: Histone deacetylase inhibitors and cancer: from cell biology to the clinic. Eur J Cell Biol 84: 109-121, 2005.

8. Monneret C: Histone deacetylase inhibitors. Eur J Med Chem 40: 1-13, 2005.

9. Minucci S and Pelicci PG: Histone deacetylase inhibitors and the promise of epigenetic (and more) treatments for cancer. Nat Rev Cancer 6: 38-51, 2006.

10. Qiu L, Kelso MJ, Hansen C, West ML, Fairlie DP and Parsons PG: Anti-tumour activity in vitro and in vivo of selective differentiating agents containing hydroxamate. Br J Cancer 80: 1252-1258, 1999.

11. Marks PA, Richon VM, Miller T and Kelly WK: Histone deacetylase inhibitors. Adv Cancer Res 91: 137-168, 2004.

12. Atadja P, Gao L, Kwon P, Trogani N, Walker H, Hsu M, Yeleswarapu L, Chandramouli N, Perez L, Versace R, Wu A, Sambucetti L, Lassota P, Cohen D, Bair K, Wood A and Remiszewski S: Selective growth inhibition of tumor cells by a novel histone deacetylase inhibitor, NVP-LAQ824. Cancer Res 64: 689-695, 2004.

13. Kim MS, Kwon HJ, Lee YM, Baek JH, Jang JE, Lee SW, Moon EJ, Kim HS, Lee SK, Chung HY, Kim CW and Kim KW: Histone deacetylases induce angiogenesis by negative regulation of tumor suppressor genes. Nat Med 7: 437-443, 2001.

14. Nakano K, Mizuno T, Sowa Y, Orita T, Yoshino T, Okuyama Y, Fujita T, Ohtani-Fujita N, Matsukawa Y, Tokino T, Yamagishi H, Oka T, Nomura $\mathrm{H}$ and Sakai T: Butyrate activates the WAF1/Cip1 gene promoter through Sp1 sites in a p53-negative human colon cancer cell line. J Biol Chem 272: 22199-22206, 1997.

15. Sowa Y, Orita T, Minamikawa S, Nakano K, Mizuno T, Nomura $\mathrm{H}$ and Sakai T: Histone deacetylase inhibitor activates the WAF1/Cip1 gene promoter through the Sp1 sites. Biochem Biophys Res Commun 241: 142-150, 1997.
16. Archer SY, Meng S, Shei A and Hodin RA: p21(WAF1) is required for butyrate-mediated growth inhibition of human colon cancer cells. Proc Natl Acad Sci USA 95: 6791-6796, 1998.

17. Sato N, Ohta T, Kitagawa H, Kayahara M, Ninomiya I, Fushida S, Fujimura T, Nishimura G, Shimizu K and Miwa K: FR901228, a novel histone deacetylase inhibitor, induces cell cycle arrest and subsequent apoptosis in refractory human pancreatic cancer cells. Int J Oncol 24: 679-685, 2004.

18. Guo F, Sigua C, Tao J, Bali P, George P, Li Y, Wittmann S, Moscinski L, Atadja P and Bhalla K: Cotreatment with histone deacetylase inhibitor LAQ824 enhances Apo-2L/tumor necrosisfactor-related apoptosis inducing ligand-induced death inducing signaling complex activity and apoptosis of human acute leukemia cells. Cancer Res 64: 2580-2589, 2004.

19. Shao Y, Gao Z, Marks PA and Jiang X: Apoptotic and autophagic cell death induced by histone deacetylase inhibitors. Proc Natl Acad Sci USA 101: 18030-18035, 2004.

20. Ungerstedt JS, Sowa Y, Xu WS, Shao Y, Dokmanovic M, Perez G, Ngo L, Holmgren A, Jiang X and Marks PA: Role of thioredoxin in the response of normal and transformed cells to histone deacetylase inhibitors. Proc Natl Acad Sci USA 102: 673-678, 2005.

21. Piekarz R and Bates S: A review of depsipeptide and other histone deacetylase inhibitors in clinical trials. Curr Pharm Des 10: 2289-2298, 2004.

22. O'Connor OA, Heaney ML, Schwartz L, Richardson S, Willim R, MacGregor-Cortelli B, Curly T, Moskowitz C, Portlock C, Horwitz S, Zelenetz AD, Frankel S, Richon V, Marks P and Kelly WK: Clinical experience with intravenous and oral formulations of the novel histone deacetylase inhibitor suberoylanilide hydroxamic acid in patients with advanced hematologic malignancies. J Clin Oncol 24: 166-173, 2006.

23. Kelly WK, O'Connor OA, Krug LM, Chiao JH, Heaney M, Curley T, MacGregore-Cortelli B, Tong W, Secrist JP, Schwartz L, Richardson S, Chu E, Olgac S, Marks PA, Scher H and RichonVM: Phase I study of an oral histone deacetylase inhibitor, suberoylanilide hydroxamic acid, in patients with advanced cancer. J Clin Oncol 23: 3923-3931, 2005.

24. Kelly WK, Richon VM, O'Connor O, Curley T, MacGregorCurtelli B, Tong W, Klang M, Schwartz L, Richardson S, Rosa E, Drobnjak M, Cordon-Cordo C, Chiao JH, Rifkind R, Marks PA and Scher H: Phase I clinical trial of histone deacetylase inhibitor: suberoylanilide hydroxamic acid administered intravenously. Clin Cancer Res 9: 3578-3588, 2003.

25. Marks PA and Breslow R: Dimethyl sulfoxide to vorinostat: development of this histone deacetylase inhibitor as an anticancer drug. Nat Biotechnol 25: 84-90, 2007.

26. Piekarz RL, Robey R, Sandor V, Bakke S, Wilson WH, Dahmoush L, Kingma DM, Turner ML, Altemus R and Bates SE: Inhibitor of histone deacetylation, depsipeptide (FR901228), in the treatment of peripheral and cutaneous T-cell lymphoma: a case report. Blood 98: 2865-2868, 2001.

27. Masuoka Y, Nagai A, Shin-ya K, Furihata K, Nagai K, Suzuki K, Hayakawa Y and Seto H: Spiruchostatins A and B, novel gene expression enhancing substances produced by Pseudomonas sp. Tetrahedron Lett 42: 41-44, 2001.

28. Yoshida M, Kijima M, Akita M and Beppu T: Potent and specific inhibition of mammalian histone deacetylase both in vivo and in vitro by trichostatin A. J Biol Chem 265: 17174-17179, 1990.

29. Nare B, Allocco JJ, Kuningas R, Galuska S, Myers RW, Bednarek MA and Schmatz DM: Development of a scintillation proximity assay for histone deacetylase using a biotinylated peptide derived from histone-H4. Anal Biochem 267: 390-396, 1999.

30. Finnin MS, Donigian JR, Cohen A, Richon VM, Rifkind RA, Marks PA, Breslow R and Pavletich NP: Structures of a histone deacetylase homologue bound to the TSA and SAHA inhibitors. Nature 401: 188-193, 1999.

31. Jones G, Willett P and Glen RC: Molecular recognition of receptor sites using a genetic algorithm with a description of desolvation. J Mol Biol 245: 43-53, 1995.

32. Papazisis KT, Geromichalos GD, Dimitriadis KA and Kortsaris AH: Optimization of the sulforhodamine B colorimetric assay. J Immunol Methods 208: 151-158, 1997.

33. Nakata S, Yoshida T, Horinaka M, Shiraishi T, Wakada M and Sakai T: Histone deacetylase inhibitors upregulate death receptor 5/TRAIL-R2 and sensitize apoptosis induced by TRAIL/APO2-L in human malignant tumor cells. Oncogene 23: 6261-6271, 2004. 
34. Furumai R, Komatsu Y, Nishino N, Khochbin S, Yoshida M and Horinouchi S: Potent histone deacetylase inhibitors built from trichostatin A and cyclic tetrapeptide antibiotics including trapoxin. Proc Natl Acad Sci USA 98: 87-92, 2001.

35. Furumai R, Matsuyama A, Kobashi N, Lee KH, Nishiyama M, Nakajima H, Tanaka A, Komatsu Y, Nishino N, Yoshida M and Horinouchi S: FK228 (depsipeptide) as a natural prodrug that inhibits class I histone deacetylases. Cancer Res 62: 4916-4921, 2002.

36. Yokomizo A, Ono M, Nanri H, Makino Y, Ohga T, Wada M, Okamoto T, Yodoi J, Kuwano M and Kohno K: Cellular levels of thioredoxin associated with drug sensitivity to cisplatin, mitomycin C, doxorubicin, and etoposide. Cancer Res 55: 4293-4296, 1995.

37. Balendiran GK, Dabur R and Fraser D: The role of glutathione in cancer. Cell Biochem Funct 22: 343-352, 2004.

38. Butler LM, Agus DB, Scher HI, Higgins B, Rose A, Cordon-Cardo C, Thaler HT, Rifkind RA, Marks PA and Richon VM: Suberoylanilide hydroxamic acid, an inhibitor of histone deacetylase, suppresses the growth of prostate cancer cells in vitro and in vivo. Cancer Res 60: 5165-5170, 2000.
39. Vanhaecke T, Papeleu P, Elaut G and Rogiers V: Trichostatin A-like hydroxamate histone deacetylase inhibitors as therapeutic agents: toxicological point of view. Curr Med Chem 11: 1629-1643, 2004.

40. Hyodo F, Matsumoto K, Matsumoto A, Mitchell JB and Krishna MC: Probing the intracellular redox status of tumors with magnetic resonance imaging and redox-sensitive contrast agents. Cancer Res 66: 9921-9928, 2006.

41. Kuppusamy P, Li H, Ilangovan G, Cardounel AJ, Zweier JL, Yamada K, Krishna MC and Mitchell JB: Non-invasive imaging of tumor redox status and its modification by tissue glutathione levels. Cancer Res 62: 307-312, 2002.

42. Maeda H, Wu J, Sawa T, Matsumura Y and Hori K: Tumor vascular permeability and the EPR effect in macromolecular therapeutics: a review. J Control Release 65: 271-284, 2000. 